Journal Of Metallurgical Engineering And Processing Technology, Vol. 2, No. 2, February 2022, pp. 75-79

P-ISSN: 2723-6854, E-ISSN: 2798-1037

\title{
PENGARUH PROSES QUENCHING-TEMPERING DALAM MENINGKATKAN SIFAT MEKANIK PIPA LOW CARBON STEEL LOW ALLOY GRADE J55 MENJADI GRADE P110
}

\author{
Muhammad Agris Setiawan', Herodes Eka Putra Tambunan ${ }^{2}$ \\ Program Studi Teknik Metalurgi - Fakultas Teknologi Mineral \\ UPN "Veteran” Yogyakarta, Jl. Padjadjaran, Condongcatur, Yogyakarta 55283 \\ Email : $\underline{\text { rherodesputra@gmail.com }}{ }^{2}$
}

\begin{abstract}
Steel is a metal alloy with iron as the basic element and carbon as the main alloy. The carbon content in steel ranges from $0.2 \%$ to $2.1 \%$ by weight depending on the grade. The function of carbon in steel is as a hardener. Other alloying elements commonly added besides carbon are manganese, chromium, vanadium, and nickel. By varying the content of carbon and other alloying elements, various types of steel qualities can be obtained. The addition of carbon content in steel can increase its hardness and tensile strength, but on the other hand it becomes brittle and reduces its ductility. The heat treatment process or heat treatment process is carried out on a material in terms of metal with the aim of obtaining certain mechanical properties (as desired). To achieve this goal is generally to perform operations between heating and cooling. The material at a certain temperature, held for a certain time and followed by cooling with a certain cooling rate.
\end{abstract}

Keywords : steel, heat treatment

\begin{abstract}
ABSTRAK
Baja adalah logam paduan dengan besi sebagai unsur dasar dan karbon sebagai unsur paduan utamanya. Kandungan karbon dalam baja berkisar antara $0.2 \%$ hingga $2.1 \%$ berat sesuai gradenya. Fungsi karbon dalam baja adalah sebagai unsur pengeras. Unsur paduan lain yang biasa ditambahkan selain karbon adalah mangan, krom, vanadium, dan nikel. Dengan memvariasikan kandungan karbon dan unsur paduan lainnya, berbagai jenis kualitas baja bisa didapatkan. Penambahan kandungan karbon pada baja dapat meningkatkan kekerasan dan kekuatan tariknya, namun di sisi lain membuatnya menjadi getas serta menurunkan keuletannya. Proses heat treament atau proses perlakuan panas yang dilakukan terhadap sesuatu material dalam hal ini logam dengan tujuan untuk mendapatkan sifat mekanik tertentu (sesuai dengan keinginan). Untuk mencapai tujuan tersebut pada umumnya dengan melakukan kombinasi pengoperasian antara pemanasan dan pendinginan. Material dipanaskan pada temperature tertentu, ditahan dengan waktu penahanan tertentu dan diikuti dengan pendinginan dengan laju pendinginan tertentu.
\end{abstract}

Kata kunci : baja, heat treatment 


\section{Pendahuluan}

Menenggarai sebagai negara komoditas tambang seperti minyak dan gas bumi yang lumayan besar, Indonesia butuh pasokan pipa baja yang besar pula. Berbagai jenis kebutuhan dari berbagai jenis serta ukuran guna menunjang kegiatan eksplorasi, produksi hingga distribusi harus tersedia dalam jumlah memadai. Proses pembuatan pipa baja depat dilakukan dengan bahan baku material billet baja paduan yang diproses secara hot rolling mill dan heat treatment. Setiap sebelum dilakukan proses produksi dalam skala yang besar, dilakukan uji sampel material hasil heat treatment menggunakan alat uji tarik guna memperoleh standarisasi temperature perlakuan panas yang sesuai sehingga menghasilkan grade pipa dengan standar seperti yang terdapat pada buku API Specification 5CT. Uji tarik material dilakukan karena pipa memiliki syaratsyarat yang harus dipenuhi sebelum nantinya di aplikasikan ke lapangan. Syarat-syarat ini meliputi nilai kekuatan luluh serta kekuatan tarik minimum hingga maksimum dari pipa. Temperature heat treatment yang tidak sesuai akan mempengaruhi sifat mekanis dari masingmasing produk, sehingga perlu diperhatikan dengan baik.

Pada jurnal ini akan mempelajari seberapa besar pengaruh dari perlakukan panas terhadap peningkatan sifat mekanis pipa grade J55 menjadi grade P110.

\section{METODE PENELITIAN}

Metode penelitian menggunakan data sekunder hasil pengujian uji tarik yang dilakukan di Laboratorium QHSE menggunakan alat Uji Tarik. Pengujian dilakukan terhadap material hasil heat treatment pada rentang waktu 08 November 2021-7 Desember 2021.

\section{Pengujian Sampel yang diberikan perlakuan quenching-tempering}

a. Preparasi sample test sehingga berbentuk seperti dog bone dengan ukuran seperti Gambar 1. Pada penelitian ini, spesimen yang digunakan memiliki OD $>7^{5 / 8}$ in.

b. Melakukan proses austenisasi sampel test pada temperatur $910{ }^{\circ} \mathrm{C}$ dengan waktu tahan 64 menit.

c. Melakukan pendinginan cepat dengan media air.

d. Melakukan proses tempering pada temperature $490^{\circ} \mathrm{C}$ dengan waktu tahan 108 menit.

e. Setelah 108 menit, sample test di keluarkan dan dibiarkan diudara terbuka hingga dingin.

f. Mengukur dimensi spesimen yang akan di uji seperti Panjang dan diameter.

g. Letakan spesimen uji tarik diantara kedua grip chuck pada mesin uji tarik dengan benar dan tegak lurus.

h. Lakukan pemberian beban tarik pada spesimen. Penarikan atau pemberian beban tarik dimulai dari nol, dengan penambahan beban secara merata agar tidak terjadi beban kejut.

i. Selama pengujian berlangsung akan terjadi pertambahan panjang dan pengecilan penampang sampai terjadinya patah atau putus.

\section{PENGOLAHAN DATA HASIL UJI KOMPOSISI}

Data yang diperoleh kemudian dianalisis hasilnya apakah setelah diberikan perlakuan panas dapat meningkatkan kemampuan mekanis dari material pipa yang sebelumnya tidak dilakukan perlakuan panas. 
Journal Of Metallurgical Engineering And Processing Technology, Vol. 2, No. 2, February 2022, pp. 75-79

P-ISSN: 2723-6854, E-ISSN: 2798-1037

\begin{tabular}{|c|c|c|c|c|c|}
\hline Pipe OD & $\begin{array}{c}\text { A } \\
\text { (WIDTH) }\end{array}$ & $\begin{array}{c}\text { B } \\
\text { (WIDTH GRIP) }\end{array}$ & $\begin{array}{c}c \\
\text { (GAUGE LENGTH) }\end{array}$ & $\begin{array}{c}\text { D } \\
\text { (REDUCE } \\
\text { SECTION) }\end{array}$ & $\begin{array}{c}\mathbf{R} \\
\text { (RADIUS) }\end{array}$ \\
\hline \multirow{2}{*}{$1-4$ in } & $\% \pm 0.031$ in & \multirow{2}{*}{1 in sekitar $25.4 \mathrm{~mm}$} & $\begin{array}{c}2 \pm 0.005 \mathrm{in} \\
(50.63-50.92 \mathrm{~mm})\end{array}$ & 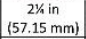 & $\begin{array}{c}1 \text { in } \\
(25.4 \mathrm{~mm}) \\
\end{array}$ \\
\hline & $18.26-19.83 \mathrm{~mm}$ & & $\begin{array}{c}4 \pm 0.005 \mathrm{in} \\
(101.47-101.72 \mathrm{~mm})\end{array}$ & \begin{tabular}{|c|}
$4 / 2 \mathrm{in}$ \\
$(114.3 \mathrm{~mm})$ \\
\end{tabular} & $\begin{array}{c}1 \text { in } \\
(25.4 \mathrm{~mm}) \\
\end{array}$ \\
\hline \multirow{2}{*}{$5.75 / 8$ in } & $1 \pm 0.062$ in & \multirow{2}{*}{$11 / 2$ in sekitar $38.1 \mathrm{~mm}$} & $\begin{array}{c}2 \pm 0.005 \mathrm{in} \\
(50.63-50.92 \mathrm{~mm})\end{array}$ & $\begin{array}{c}2 \% / 1 / \text { in } \\
(57.15 \mathrm{~mm})\end{array}$ & $\begin{array}{c}1 \text { in } \\
(25.4 \mathrm{~mm})\end{array}$ \\
\hline & 23.82-26.97 mm & & $\begin{array}{c}4 \pm 0.005 \mathrm{in} \\
(101.47-101.72 \mathrm{~mm}\}\end{array}$ & $\begin{array}{c}41 / \mathrm{in} \\
(114.3 \mathrm{~mm})\end{array}$ & $\begin{array}{c}1 \mathrm{in} \\
(25.4 \mathrm{~mm})\end{array}$ \\
\hline \multirow{2}{*}{$O D>75 / 8$ in } & $1 \% \frac{11 / 2}{0.125}$ in & \multirow{2}{*}{2 in sekitar $50.8 \mathrm{~mm}$} & $\begin{array}{c}2 \pm 0.005 \text { in } \\
(50.63-50.92 \mathrm{~mm})\end{array}$ & $\begin{array}{c}2 \% \text { in } \\
57.15 \mathrm{~mm}\end{array}$ & $\begin{array}{c}1 \mathrm{in} \\
(25.4 \mathrm{~mm})\end{array}$ \\
\hline & $35.00-41.27 \mathrm{~mm}$ & & $\begin{array}{c}4 \pm 0.005 \text { in } \\
\{101.47-101.72 \mathrm{~mm})\end{array}$ & $\begin{array}{c}41 / 2 \mathrm{in} \\
(114.3 \mathrm{~mm})\end{array}$ & $\begin{array}{c}\begin{array}{c}1 \mathrm{in} \\
(25.4 \mathrm{~mm}\end{array} \\
\end{array}$ \\
\hline
\end{tabular}

Gambar 1. Dimensi dan Toleransi Spesimen Uji Tarik

\section{HASIL DAN PEMBAHASAN}

Hasil pengujian uji tarik menggunakan Mesin Uji Tarik dari sampel test sebelum perlakuan panas dan sesudah perlakuan panas dapat dilihat pada Gambar 2-3.

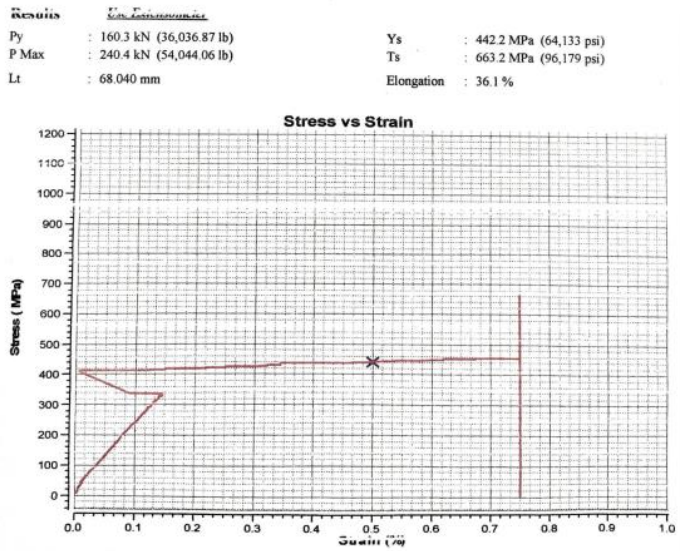

Gambar 2. Hasil Uji Tarik Spesimen pipa grade J55 tanpa perlakuan panas

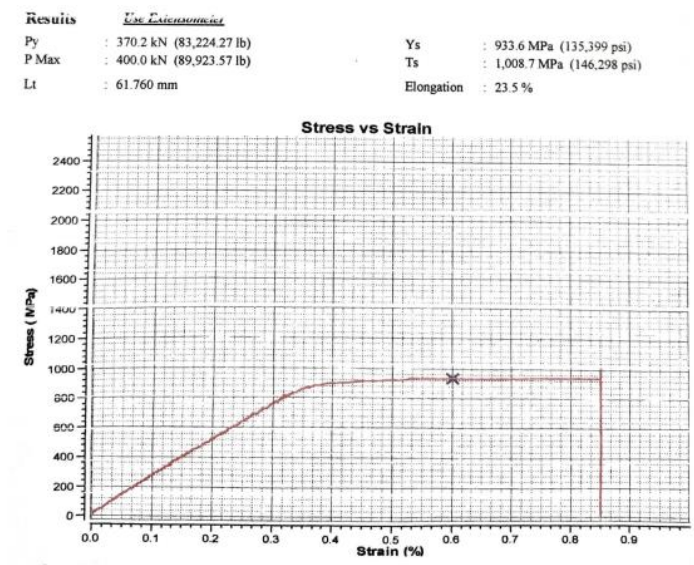

Gambar 3. Hasil Uji Tarik Spesimen J55 dengan perlakuan panas

Setelah didapatkan data hasil uji tarik tersebut menunjukan pengaruh quenching-tempering terhadap kekuatan tarik dan kekuatan luluh dari pipa grade J55. Pada spesimen pipa J55 yang tidak diberikan perlakuan quenching-tampering nilai kekuatan luluh dan kekuatan tarik masing-masing hanya senilai $442.2 \mathrm{MPa}(64,133 \mathrm{psi})$ dan 663.2 MPa (96,179 psi), sedangkan setelah diberikan perlakuan quenching-tempering, nilai kekuatan luluh dan kekuatan tarik masing-masing meningkat hingga sebesar 933.6 MPa (135,399 psi) dan 1,008.7 MPa (146,298 psi). Hasil temper yang telah dilakukan menghasilkan mikrostruktur baja homogen dan tegangan sisa akibat pemanasan yang tinggi selama di-quenching tereliminasi atau dapat diminimalisasi. Hasil pengujian ini menunjukan bahwa perlakuan quenching-tempering dapat meningkatkan sifat mekanik dari pipa baja grade J55 menjadi P110.

Tabel 1. Tensile Requirements (Casing and Tubing, API Specification 5CT)

\begin{tabular}{|c|c|c|c|c|c|}
\hline \multirow{2}{*}{$\begin{array}{l}\bigcap \\
\text { مै } \\
\text { के }\end{array}$} & \multirow{2}{*}{$\underset{\varnothing}{-~}$} & \multirow{2}{*}{$\begin{array}{c}\text { Total } \\
\text { Elonga } \\
\text { tion } \\
\text { Under } \\
\text { Load } \\
\%\end{array}$} & \multicolumn{2}{|c|}{$\begin{array}{c}\text { Yield } \\
\text { Strenghth } \\
\mathrm{MPa}\end{array}$} & \multirow{2}{*}{$\begin{array}{c}\text { Tensile } \\
\text { Strength } \\
\text { min. } \\
\mathrm{MPa}\end{array}$} \\
\hline & & & $\min$ & $\max$ & \\
\hline J55 & - & 0.5 & 379 & 552 & 517 \\
\hline P110 & - & 0.6 & 758 & 965 & 862 \\
\hline
\end{tabular}

Material baja yang memiliki struktur mikro Ferit \& Perlit, pada temperatur tinggi akan berubah menjadi struktur Austenite. Austenite inilah yang nantinya berubah menjadi Martensit pada saat dilakukannya quenching. Untuk mendapatkan martensite yang keras maka pada saat pemanasan harus terjadi struktur austenite yang dapat bertransformasi menjadi martensite. Bila pada saat pemanasan masih terdapat struktur lain setelah di-quench atau di dinginkan akan diperoleh struktur yang tidak seluruhnya martensite, dan bila struktur itu ferit maka kekerasan yang dihasilkan tidak maksimal. Apabila temperature terlalu rendah, austenite belum terbentuk atau ukurannya masih terlalu kecil, sedangkan apabila temperature terlalu tinggi maka austenite sudah terbentuk namun ukurannya terlalu besar. Sedangkan untuk waktu penahannya apa bila terlalu cepat, austenite bisa saja belum terbentuk 
Journal Of Metallurgical Engineering And Processing Technology, Vol. 2, No. 2, February 2022, pp. 75-79

P-ISSN: 2723-6854, E-ISSN: 2798-1037

dan ukurannya masih terlalu kecil dan bila terlalu lama akan mengakibatkan ukuran dari austenite yang terbentuk terlalu besar, hal ini seperti yang dibuktikan. Temperatur \& waktu pemanasan yang optimal untuk setiap baja akan berbeda-beda. Hal ini dipengaruhi oleh unsur paduan yang terdapat didalamnya.

Ketinggian suhu penemperan dan waktu tahan benda kerja tergantung pada jenis baja dan kekerasan yang dikehendaki. Temperatur temper pada tempering mempunyai pengaruh yang cukup besar dalam memperoleh kembali keuletan dari baja. Oleh karena itu perlu mengetahui dan memahami berapa tinggi temperatur pada tempering yang harus dilakukan untuk mendapatkan baja dengan karakteristik dan sifat mekanis tertentu. Proses tempering juga merubah struktur mikro dari baja. Dengan berubahnya struktur mikro maka sifat mekanis pada baja juga akan mengalami perubahan. Bila suhu temper meningkat, martensite terurai lebih cepat. Unsur paduan mempunyai pengaruh yang berarti pada proses tempering, yaitu menghambat laju pelunakan sehingga baja paduan akan memerlukan suhu temper yang lebih tinggi untuk memperoleh kekerasan tertentu. Pengaruh waktu tahan juga perlu diperhatikan. Meskipun pelunakan terjadi pada saat-saat pertama setelah suhu temper tercapai, selama proses tempering (yang cukup lama) akan terjadi penurunan kekerasan. Sehingga untuk baja perlu diperhatikan suhu dan waktu tahan untuk mendapatkan harga kekerasan dan ketangguhan yang diinginkan.

\section{KESIMPULAN}

Dari hasil analisis data dan pembahasan didapatkan kesimpulan dari sebagai berikut :

a. Dari hasil pengujian tarik pada spesimen pipa grade J55 sebelum di berikan perlakuan heat treatment didapatkan nilai kekuatan luluh dan kekuatan tarik masingmasing 442.2 MPa (64,133 psi) dan 663.2 MPa (96,179 psi)

b. Dari hasil pengujian tarik pada spesimen pipa grade J55 sesudah di berikan perlakuan heat treatment didapatkan nilai kekuatan luluh dan kekuatan tarik masing- masing 933.6 $\mathrm{MPa}(135,399 \mathrm{psi})$ dan 1,008.7 MPa (146,298 psi)

c. Dari hasil pengujian tarik yang dilakukan, pipa low carbon stell low alloy Grade J55 yang diberikan proses austenisasi $910^{\circ} \mathrm{C}$ dengan waktu tahan 64 menit lalu di quenching dengan media air di lanjut dengan proses tempering dengan temperature $490^{\circ} \mathrm{C}$ dengan waktu tahan 108 menit didapatkan spesimen yang memiliki kekuatan luluh dan kekuatan tarik yang memenuhi tensile requirements pipa grade P110.

d. Dari hasil proses heat treatment didapatkan sifat mekanik material yang diinginkan.

\section{DAFTAR PUSTAKA}

Affandi, Muhammad dkk. Analisa Pengaruh Waktu Penahanan pada Proses Quenching-Portitioning Terhadap Sifat Mekanik dan Struktur Mikro Baja Jis Sup 9A. Teknik Desain dan Manufaktur. Surabaya : Politeknik Negeri Perkapalan. Alfianto, Revan Pajar. 2021. Pengaruh

Proses Quenching dan Tempering Dengan Variasi Holding Time 10,30 dan 60 menit Terhadap Nilai Kekerasan dan Struktur Mikro Baja Karbon Sedang. Skripsi. Teknik Mesin. Universitas Muhammadiyah Surakarta.

Ginting, Ediman. dkk. Pengaruh Variasi

Waktu Tahan Austenisasi dengan

Pendinginan Cepat terhadap Kekerasan dan Ketangguhan Baja AISI 1045. 2020. Jurnal Riset. DOI :

10.22146/jfi.v24i1.54038

Haryadi, Gunawan Dwi. Pengaruh Suhu

Tempering Terhadap Kekerasan,

Kekuatan Tarik dan Struktur Mikro pada Baja K-46.

Irawati, Herlina. 2017. ANALISA

PENGARUH VARIASI WAKTU

PENAHANAN AUSTENISASI PADA

PERLAKUAN PANAS PENGERASAN 
Journal Of Metallurgical Engineering And Processing Technology, Vol. 2, No. 2, February 2022, pp. 75-79

P-ISSN: 2723-6854, E-ISSN: 2798-1037

TERHADAP STRUKTUR MIKRO, NILAI

KEKERASAN DAN KEKUATAN IMPAK

PADA BAJA KARBON AISI 1050. Tugas

Akhir. Industrial Mechanical Engineering.

Institute Technology of Sepuluh Nopember,

Surabaya. 